This item was submitted to Loughborough's Research Repository by the author.

Items in Figshare are protected by copyright, with all rights reserved, unless otherwise indicated.

\title{
Selection of mould design variables in direct stereolithography injection mould tooling
}

PLEASE CITE THE PUBLISHED VERSION

PUBLISHER

Professional Engineering Publishing / @ IMechE

VERSION

VoR (Version of Record)

LICENCE

CC BY-NC-ND 4.0

\section{REPOSITORY RECORD}

Harris, Russell A., H.A. Newlyn, and Phill M. Dickens. 2019. "Selection of Mould Design Variables in Direct Stereolithography Injection Mould Tooling”. figshare. https://hdl.handle.net/2134/4725. 
This item was submitted to Loughborough's Institutional Repository (https://dspace.lboro.ac.uk/) by the author and is made available under the following Creative Commons Licence conditions.

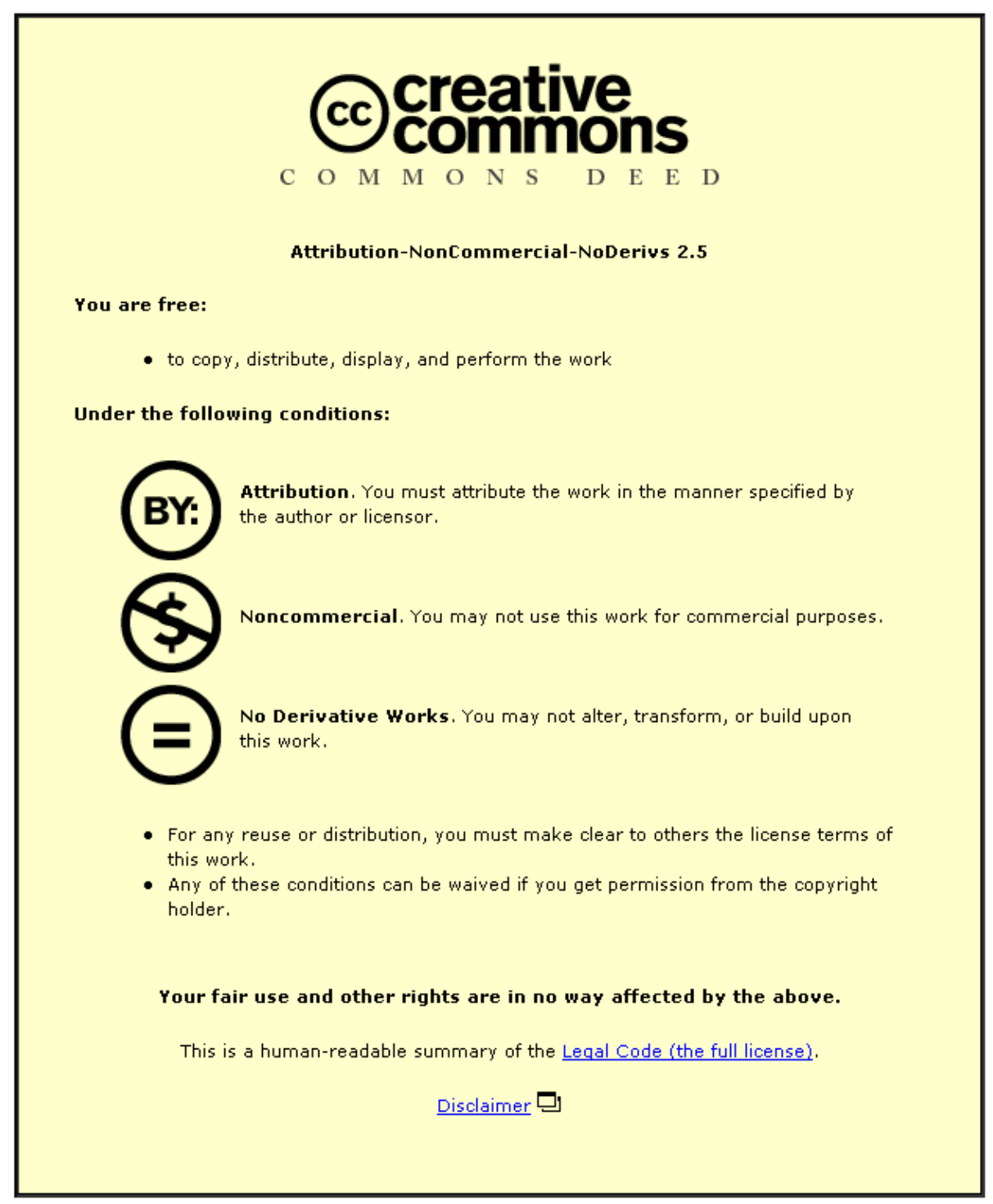

For the full text of this licence, please go to: http://creativecommons.org/licenses/by-nc-nd/2.5/ 


\title{
Selection of mould design variables in direct stereolithography injection mould tooling
}

\author{
R A Harris*, H A Newlyn and P M Dickens \\ Rapid Manufacturing Group, Wolfson School of Mechanical and Manufacturing Engineering, Loughborough \\ University, Leicestershire, UK
}

\begin{abstract}
Stereolithography (SL) can be used rapidly to produce injection moulding tools. The disadvantage of the technique is that it is capable of producing only a small number of parts before failure. Stereolithography tools may break under the force exerted by part ejection when the friction between a moulding and a feature of the tool is greater than the tensile strength of the tool, resulting in tensile failure.

Very few justified recommendations exist concerning the choice of mould design variables that can lower the part ejection force experienced and reduce the risk of SL tool failure. This research investigates the ejection forces resulting from the injection moulding of polypropylene (PP), acrylonitrile-butadiene-styrene (ABS) and polyamide 66 (PA66) parts from SL tools that are identical in all respects except for their build layer thickness (a process variable when generating the SL tooling cavities) and incorporated draft angles (a tooling design variable). This work attempts to identify appropriate evidence for recommendations with respect to these variables and SL injection moulding.

The results show that linear adjustment of draft angle results in a fairly minor linear change in part ejection force according to the moulding material. A linear adjustment of the build layer thickness results in a greater change in part ejection force as a more non-linear relationship. In both cases the greatest ejection forces were experienced by PA66, then ABS and then the PP parts. The results also show that the surface roughness of all tools remains unchanged after moulding a number of parts in all polymers.

A mathematical model was used in an attempt to predict ejection forces according to the moulding material used. This model did reflect the experimental results in terms of relative values but not in absolute values, which may be due to the limitations imposed by the development of the expressions and uncertainty about some specific values.
\end{abstract}

Keywords: stereolithography, rapid tooling, injection moulding, mould design

\section{NOTATION}

$E \quad$ Young's modulus of the moulding material at $T_{\mathrm{e}}$ $(\mathrm{MPa})$

$F_{\mathrm{e}} \quad$ ejection force $(\mathrm{N})$

$L \quad$ length of the core $(\mathrm{mm})$

$t \quad$ thickness of the moulding (mm)

$T_{\mathrm{e}} \quad$ ejection temperature of the moulding material $\left({ }^{\circ} \mathrm{C}\right)$

$T_{\mathrm{m}} \quad$ melting temperature of the moulding material $\left({ }^{\circ} \mathrm{C}\right)$ $\alpha \quad$ coefficient of thermal expansion of the moulding material $\left(\mathrm{K}^{-1}\right)$

$\mu \quad$ coefficient of friction between the moulding material and the core

$\nu \quad$ Poisson's ratio for the moulding material

\section{INTRODUCTION}

Models produced by rapid prototyping (RP) allow the validation of the design of a part with respect to its geometry. Beyond this, the RP technique of stereolithography (SL), when used to manufacture moulding cavities, has shown itself to be capable of rapidly and economically producing low volumes of plastic injection moulded parts prior to commitment to hard tooling.
The MS was received on 13 August 2001 and was accepted after revision for publication on 13 December 2001.

*Corresponding author: Rapid Manufacturing Group, Wolfson School of Mechanical and Manufacturing Engineering, Loughborough University, Leicestershire LE11 3TU, UK. 
These parts are more complete prototypes and imitate parts that would be produced by a hard tooling manner with respect to their material, geometry and production process.

During the early years of SL it was never envisaged that this process could be used directly to produce tooling. The glass transition temperature of SL parts available was only $\sim 65^{\circ} \mathrm{C}$, while the typical temperature of an injected polymer is $>200^{\circ} \mathrm{C}$. Despite these supposed limits, successful results were achieved by SL users worldwide, including the Danish Technological Institute, Ciba Specialty Chemicals (now Vantico), the Fraunhofer Institute, the Queensland Manufacturing Institute and Xerox Corporation [1].

Other methods exist that could be used to create the required tooling to produce such mouldings, including resin cast moulds. These processes have been compared with SL injection moulding [2] in the production of a typical quantity of parts, where the SL moulding process was found to be a superior alternative for producing design-intent prototypes.

Stereolithography injection moulding has also been compared with other direct RP mould generating techniques for producing a typical development quantity of mouldings. These RP methods included Cubital Solider (acrylic), EOS and sintered glass filled nylon [3]. Of these moulds, only the SL moulds successfully produced the required number of parts and, furthermore, were still capable of producing further mouldings at the end of the trials.

It has also been noted that some of the other alternative techniques involve additional steps in the process, therefore becoming an indirect process and not really rapid tooling [4]. Other advantages of the process have been highlighted beyond the prototype validation phase; since the tool design has been verified, the lead time and cost involved in the manufacture of production tooling has been reduced [5].

The most common source of failure in SL moulds has been described as the result of the required moulding contracting on to features in the core, causing these features to break during ejection [6]. Low tool strength, especially at elevated temperatures, has been cited as a contributory factor to failure.

Recommendations for use of SL tools published by 3D Systems suggest that an extensive cooling period is needed prior to part ejection [7]. However, research carried out at De Montfort University has suggested that as short a cooling time as possible should be adopted in order to gain a successful moulding [8]. After part ejection, the tool should be allowed to cool sufficiently before the next part is moulded.

The ejection force required in injection moulding is governed by the friction that exists between the mould and the moulded part and any effects caused by partial vacuums as the part is pushed from the mould. The friction force is a function of the normal reaction between the mould and moulding, the coefficient of static friction between the mould and moulding and the area of contact between the mould and moulding parallel to the direction of ejection [9].

Previous research has shown that the cooling time prior to ejection affects the normal reaction between the mould and moulding and therefore affects the ejection force required. By using different tools with identical dimensions, the effects of partial vacuums may be nullified, and, by using a constant cooling time (and hence a constant normal reaction between the mould and moulding), the effects of the coefficient of static friction may be assessed [8]. For most material combinations the coefficient of friction between two bodies is governed by the surface roughness of their contacting surfaces. Stereolithography parts may be built with a different layer thickness which in turn results in different values of surface roughness. Tooling draft is used to reduce the force required for part removal. The extent of this draft angle results in the amount of change required to the geometry of a part/cavity. This research is aimed at assessing the effects of the layer thickness and tooling draft angle on the ejection force required.

\section{RESEARCH METHODOLOGY}

\subsection{Tool design}

The tool design in this research is based on assessing the force required to remove a moulding from a singular, cylindrical core feature. The moulding consists of a sprue, a closed cylinder which freezes onto the core and a lower flange which the ejection pins act upon. The cylinder is $40 \mathrm{~mm}$ long with a $20 \mathrm{~mm}$ outside diameter and $2 \mathrm{~mm}$ wall thickness. Three ejector pin holes are built into the core insert to facilitate part ejection. In order to assess the effects of layer thickness on ejection forces, three sets of inserts were produced. These inserts had layer thicknesses of $0.05,0.1$ and $0.15 \mathrm{~mm}$. In order to assess the effects of tooling draft angle on ejection forces, another three sets of inserts were produced. These inserts had draft angles of $0.5,1$ and $1.5^{\circ}$. All inserts were produced on an SLA350 SL machine using SL5190 resin. The inserts were oriented in the SLA vat in such a way as to ensure that the direction of ejection would be perpendicular to the layers (i.e. in the direction of the $Z$ axis). The SL tool inserts, along with a moulding, can be seen in Fig. 1.

\subsection{Measurement of the surface roughness}

Surface roughness measurements of the central core feature were made before and after moulding to assess any reduction that may occur during the moulding 


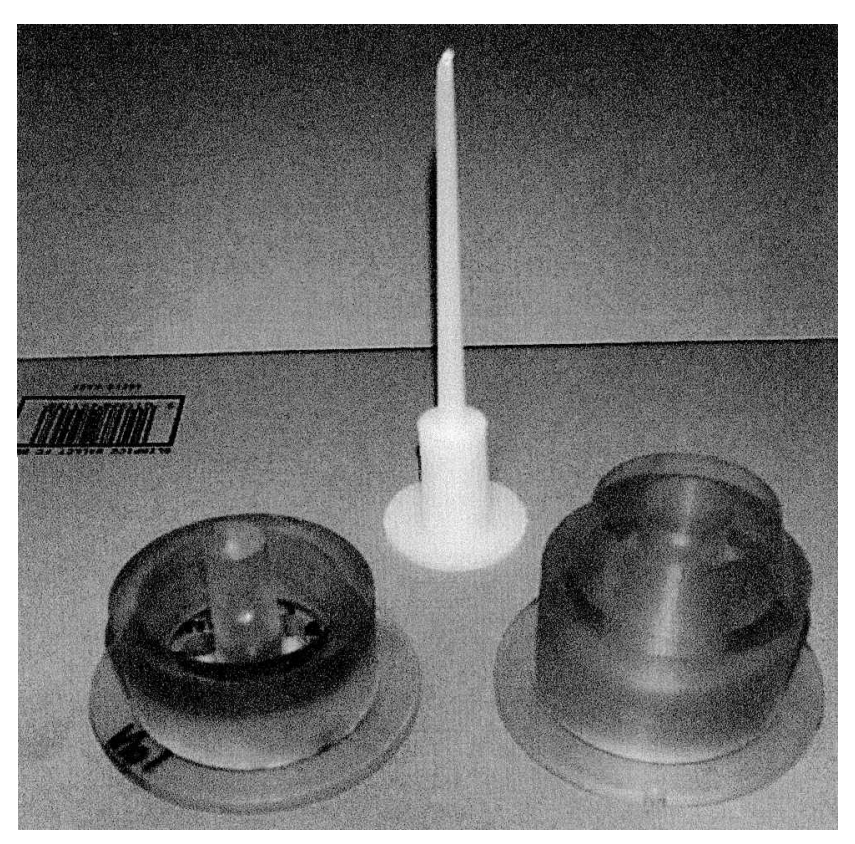

Fig. 1 Stereolithography tool with moulding

process. Measurements of surface roughness were made at 12 fixed positions (to ensure repeatability between results). Six equally spaced points around the circumference of the core $7 \mathrm{~mm}$ from the base were measured for surface roughness. Another six equally spaced points around the core were measured at a distance of $7 \mathrm{~mm}$ from the top of the core.

\subsection{Injection moulding parameters}

The ejection forces were measured for 15 parts from each tool. Silicone-based release agent spray was applied to both the core and cavity inserts prior to the first and eleventh moulding. Melt injection was performed at $5 \mathrm{~cm}^{3} / \mathrm{s}$. No packing pressure was applied as no surface ripples due to cooling in the mould could be seen. A cooling period prior to ejection of $40 \mathrm{~s}$ was used, as this had proved to be the optimum time in previous experiments [8] with similar tools, allowing minimum heat to be transferred into the tool while the part is still rigid enough to withstand ejection. For each moulding, the core temperature was allowed to cool to $55^{\circ} \mathrm{C}$ before the next shot was performed, which ensured that the tool was below its glass transition, $T_{\mathrm{g}}$, at the start of each cycle. The only difference between the moulding parameters used for the three materials was the melt temperature: $185^{\circ} \mathrm{C}$ for PP, $240^{\circ} \mathrm{C}$ for ABS and $260^{\circ} \mathrm{C}$ for PA66.

\subsection{Measurement of the ejection forces}

The ejection forces required to remove a part from the mould were measured using strain gauge based load cells which were located behind the ejection pins. The
Table 1 Values used in mathematical modelling of the ejection force

\begin{tabular}{|c|c|c|c|c|c|}
\hline \multirow[b]{2}{*}{ Variable } & \multicolumn{3}{|c|}{ Value } & \multirow[b]{2}{*}{ Units } & \multirow[b]{2}{*}{ Source } \\
\hline & PP & ABS & PA66 & & \\
\hline$\alpha$ & 86 & 80 & 86 & $\mathrm{~K}^{-1} \times 10^{-6}$ & [13] \\
\hline$T_{\mathrm{m}}$ & 185 & 240 & 260 & ${ }^{\circ} \mathrm{C}$ & $\begin{array}{l}\text { PP }[\mathbf{1 4}] \\
\text { ABS }[15] \\
\text { PA66 [16] }\end{array}$ \\
\hline$T_{\mathrm{e}}$ & 132 & 151 & 163 & ${ }^{\circ} \mathrm{C}$ & Measured \\
\hline$L$ & 38 & 38 & 38 & $\mathrm{~mm}$ & \\
\hline$E$ at $T_{\mathrm{e}}$ & 245 & 262 & 269 & $\mathrm{MPa}$ & $\begin{array}{l}\text { PP }[\mathbf{1 7}] \\
\text { ABS [18] } \\
\text { PA66 [19] }\end{array}$ \\
\hline$\mu$ & 0.88 & 0.88 & 0.88 & & {$[20]$} \\
\hline$t$ & 2 & 2 & 2 & $\mathrm{~mm}$ & \\
\hline$\nu$ & 0.35 & 0.35 & 0.35 & & {$[21]$} \\
\hline
\end{tabular}

application of a force onto the pins by the ejector plate generated a reading from the load cells which was digitized using an analogue-to-digital converter. The digital signals were sampled at $1000 \mathrm{~Hz}$ and processed using HP Vee visual programming software.

\subsection{Mathematical modelling of the ejection process}

An approach that is applicable to the cylindrical tool used in these experiments is derived from thin cylinder theory. This assumes that the diametral strain due to the difference in temperature between the part and mould core is equal to the strain created by the radial pressure.

Such equations to predict the ejection force in the traditional injection moulding tools have been proposed [9-11], but none of these refer specifically to the use of epoxy tools. The equation proposed by Glanville and Denton was simplified algebraically [12] to give

$$
F_{\mathrm{e}}=\frac{\alpha\left(T_{\mathrm{m}}-T_{\mathrm{e}}\right) L E \mu \pi}{1 /(2 t)-\nu /(4 t)}
$$

These values can be found in Table 1, with the corresponding reference sources indicated. The value of $T_{\mathrm{e}}$ was established by a K-type thermocouple in a central position of the moulding cavity, so the tip was moulded into the wall of the part.

\section{RESULTS AND DISCUSSION}

\subsection{Surface roughness measurements}

The premoulding $R_{\mathrm{a}}$ measurements made from the draft angle inserts showed virtually no difference between the surface roughness of the cores for each of the draft angles utilized $-10 \mu \mathrm{m}$ each. The premoulding $R_{\mathrm{a}}$ measurements showed a strong relationship between build layer thickness and surface roughness; i.e. layer 
thicknesses of $0.15,0.1$ and $0.05 \mathrm{~mm}$ resulted in $R_{\mathrm{a}}$ values of 15,10 and $3 \mu \mathrm{m}$ respectively.

The mean $R_{\mathrm{a}}$ values of the post-moulding surface roughness for both layer thickness and draft angle tests are very similar to those found in the premoulding tests. There is no evidence to show that the tools are smoother after moulding with any of the polymers used.

The fact that there appears to be no change in surface roughness after moulding seems a little surprising at first. However, investigations into heat transfer in the core show that the heat from the moulding penetrates the core at a very slow rate $[\mathbf{8}]$. By ejecting the part after a $40 \mathrm{~s}$ cooling period, the surface of the core is above its glass transition point at the time of ejection and acts in a compliant/rubbery way. This means that the surface roughness generated by the SL layer manufacture method will act in an elastic fashion as the moulding is pushed across the core surface at ejection.

\subsection{Ejection forces}

Figure 2 indicates that cavities built with the thicker layers result in higher ejection forces in the SL moulding process for all polymers. The increase in ejection force with larger layers is consistent with the higher surface roughness measured in these tools. A larger layer thickness results in deeper surface peaks and troughs which results in a greater quantity of material needing to deform to facilitate ejection. This in turn leads to a higher ejection force.

Figure 3 indicates that greater tooling draft angles result in lower ejection forces in the SL moulding process for all polymers. This is of no surprise, as the draft is normally used to reduce the force required for removal of the part from the mould [22].

Both sets of results show that, for all the experiments, the application of a release agent prior to moulding (applied prior to shots 1 and 11) results in a sharp drop in the ejection force. A gradual increase in force is then noted in subsequent shots.

The lowering of ejection forces with the application of a silicone release agent is of very little surprise, as this lowers the friction experienced between the mould and part surfaces. The results show that this agent is not removed entirely by one shot, but rather allows a gradual increase in the ejection forces experienced over a number of shots as it is steadily removed.

These experiments have shown that, from comparison of the two sets of results, the effect of build layer thickness is greater than the tooling draft angle on the part release forces in SL injection moulding. This difference is likely to be due to the effect of changing the respective variables on the surface roughness of the SL tool surface.

\subsection{Mathematical modelling results}

It can be seen from Table 2 that the values for the mathematically predicted forces are below the lowest experimental forces experienced and considerably different to the average experimental ejection force experienced. However, the order and ratio of difference between each of the materials remains the same in both cases. Some of the differences between the predicted force and the experimental forces may be attributed to the referenced material values used in the calculations, in

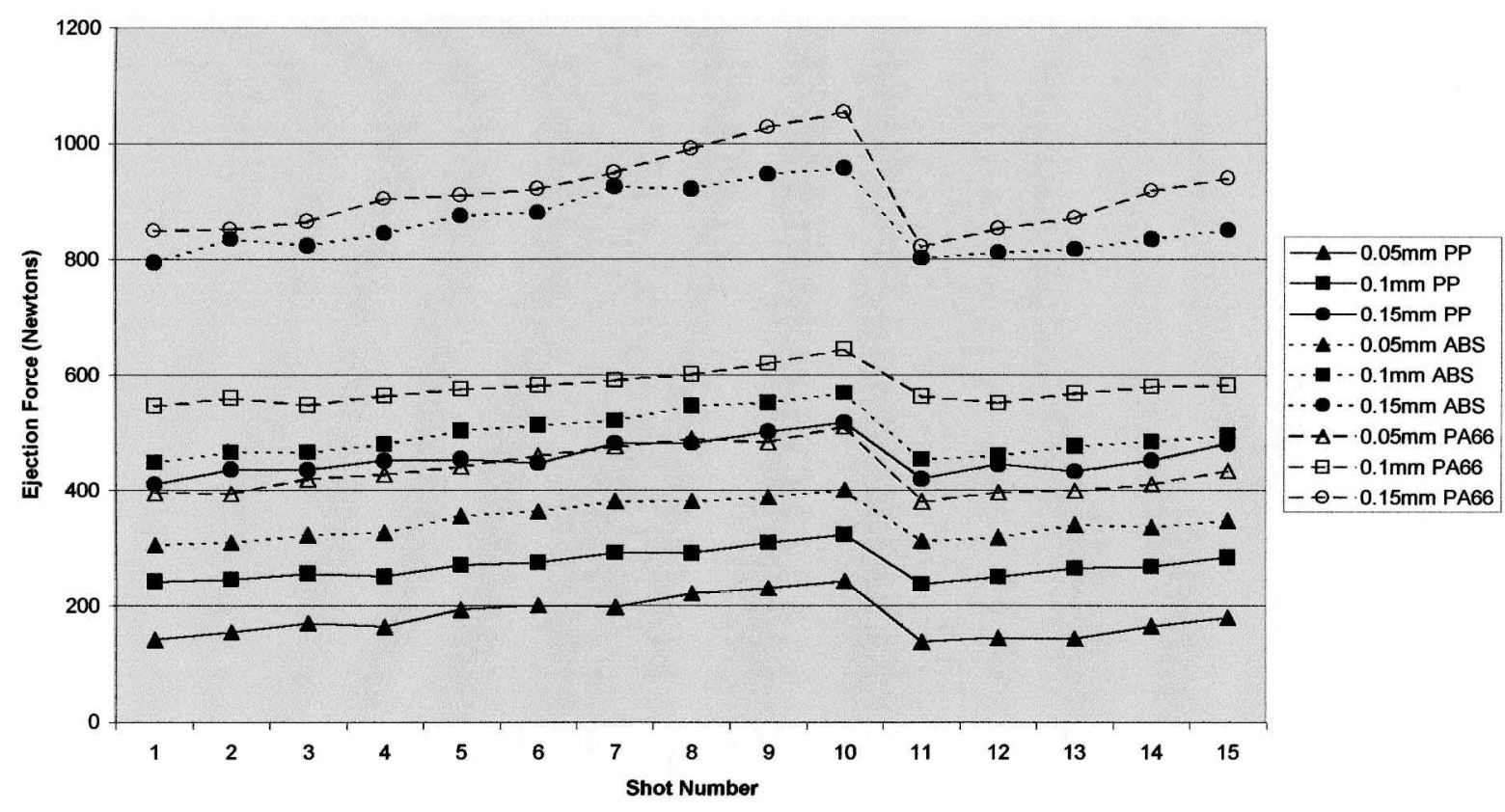

Fig. 2 Ejection forces of SL moulds of differing layer thickness with PP, ABS and PA66 


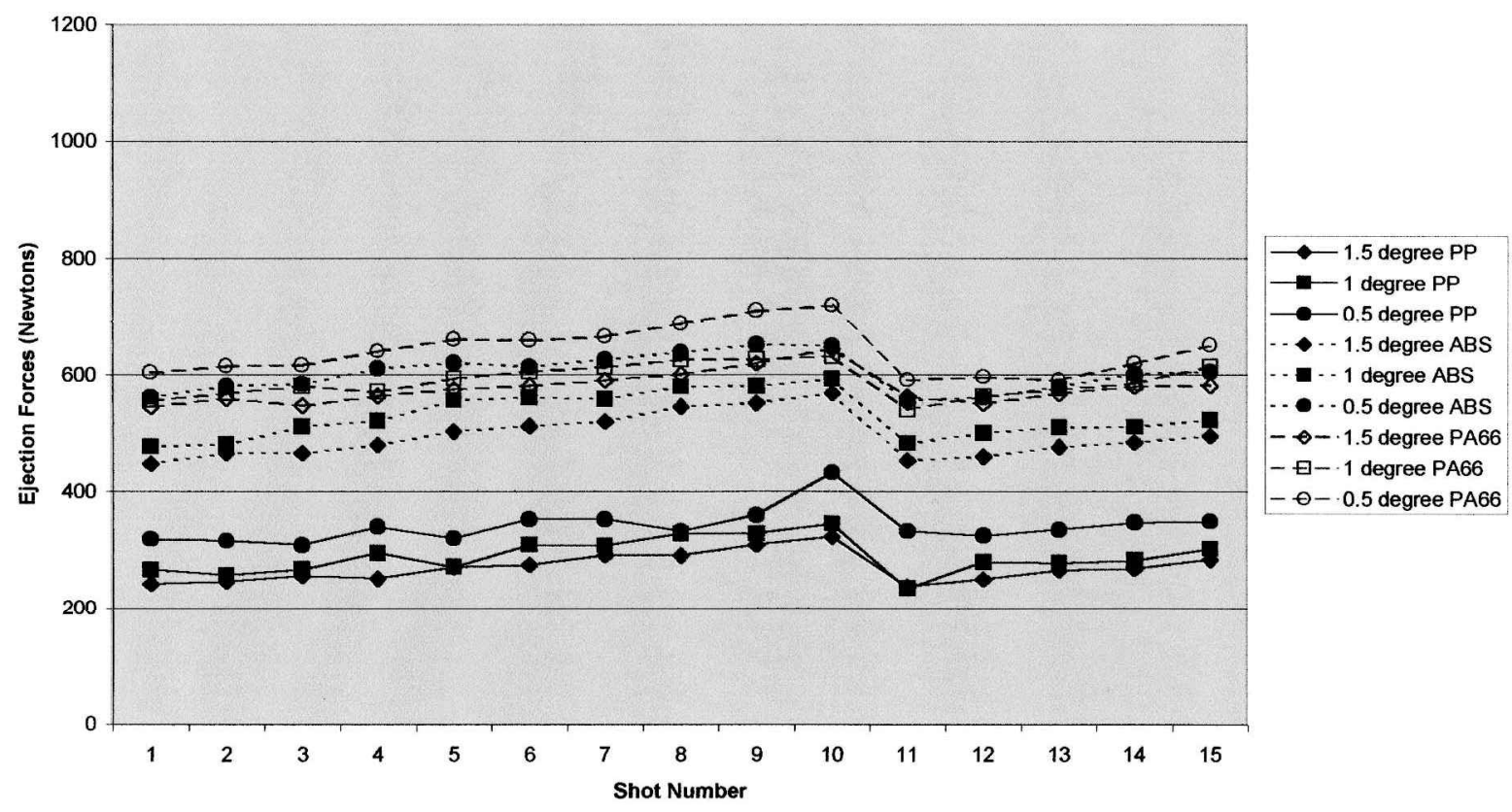

Fig. 3 Ejection forces of SL moulds of differing draft angle with PP, ABS and PA66

light of the unavailability of more specific data. This is highlighted by the value of friction used, which does not take into account the tribology of the moulding face. The experimental results show this to be a highly influential factor on the ejection force experienced.

\subsection{Moulding material}

For both experiments the greatest ejection forces were experienced by PA66, then ABS and then PP parts. The ejection forces experienced by each moulding material may be due to differences in their shrinkage characteristics and physical properties. Being semicrystalline materials, much greater shrinkage should be expected from PA66 and PP compared with ABS. However, the results show that PP demonstrates the lowest ejection force of all the polymers used. This may be due to the vast majority of PP shrinkage occurring after ejection from the tool owing to its very slow rate of shrinkage, which would be exaggerated even further by the slow heat transfer rate of SL tooling.

The rigidity of each moulding material also reflects the force required to eject a part; i.e. PP is much more flexible than PA66 and therefore more easily deformed

Table 2 Comparison of mathematical prediction and experimental forces

\begin{tabular}{lllll}
\hline Polymer & $\begin{array}{l}\text { Modelled } \\
\text { prediction } \\
(\mathrm{N})\end{array}$ & $\begin{array}{l}\text { Minimum } \\
\text { experimental } \\
\text { force }(\mathrm{N})\end{array}$ & $\begin{array}{l}\text { Median average } \\
\text { experimental } \\
\text { force }(\mathrm{N})\end{array}$ & $\begin{array}{l}\text { Maximum } \\
\text { experimental } \\
\text { force (N) }\end{array}$ \\
\hline PP & 122 & 137 & 327 & 517 \\
ABS & 205 & 307 & 640 & 973 \\
PA66 & 246 & 398 & 726 & 1054 \\
\hline
\end{tabular}

upon ejection, reducing the friction between the part and tool surfaces, which results in a lower ejection force.

\section{CONCLUSIONS}

The research presented in this paper indicates that smaller layer thicknesses and greater draft angles result in lower ejection forces and may reduce the possibility of tool failure during part ejection. Unfortunately, building parts with smaller layers involves extra time and cost, while the use of a high draft angle places compromises on the intended geometrical design of a part.

However, the results also show in both experimental cases (although much less so for the draft angle experiments) that a linear change in an experimental variable (the amount of draft angle or the build layer thickness) equates to a non-linear degree of change in the part ejection force, which is demonstrated graphically in Fig. 4 for one shot from the experimental series (shot 6). These trends may indicate the optimum values for the experimental variables which would incur the lowest part ejection force while allowing minimum disruption to the intended geometry (draft angle) of a part and minimum compromise to SL build time (layer thickness).

The ejection force experienced has also been demonstrated to be dependent on the polymer used and, while no indications of wear occurred during the experiments, it must be remembered that the number of shots involved in the experiments was very small, the materials used were relatively non-aggressive (i.e. in comparison with glass-filled polymers, etc.) and the part geometry was simple. 
Non-linear relationship between layer thickness \& ejection force

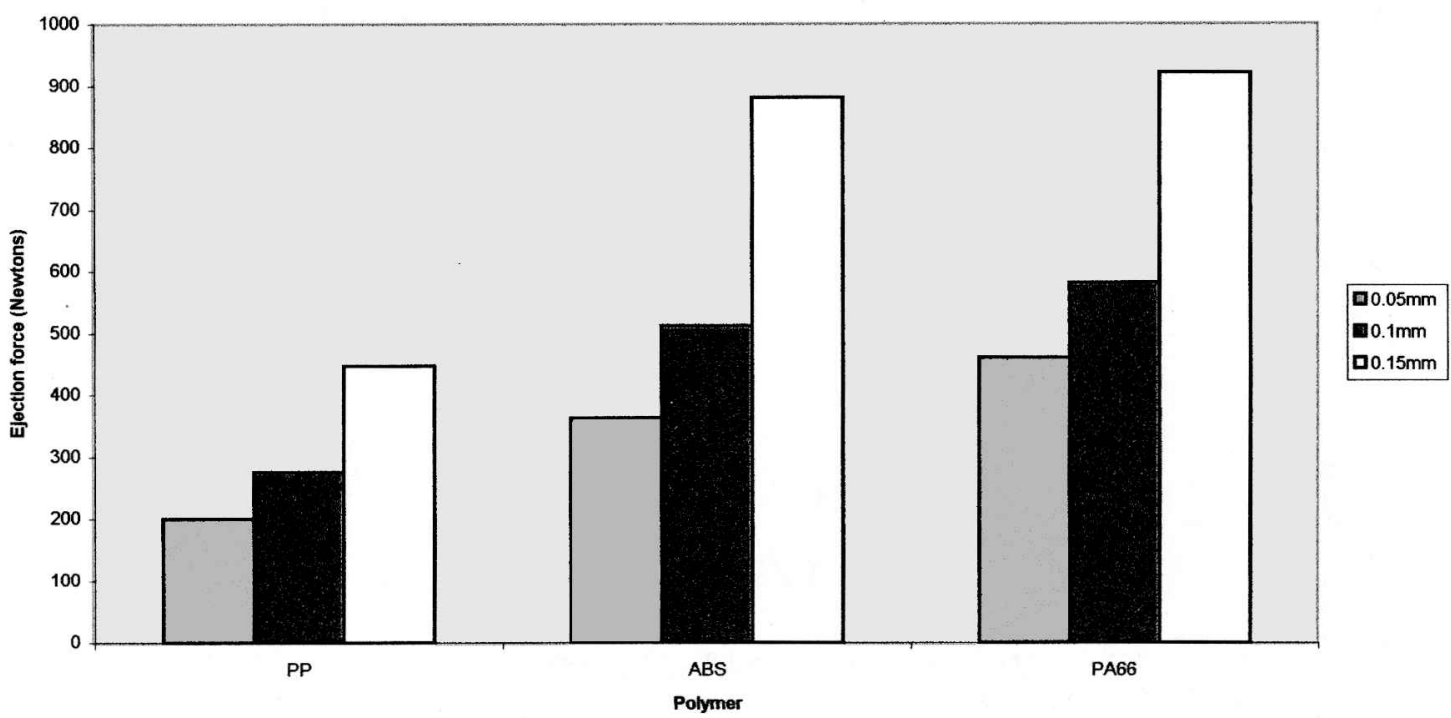

Linear relationship between draft angle \& ejection force

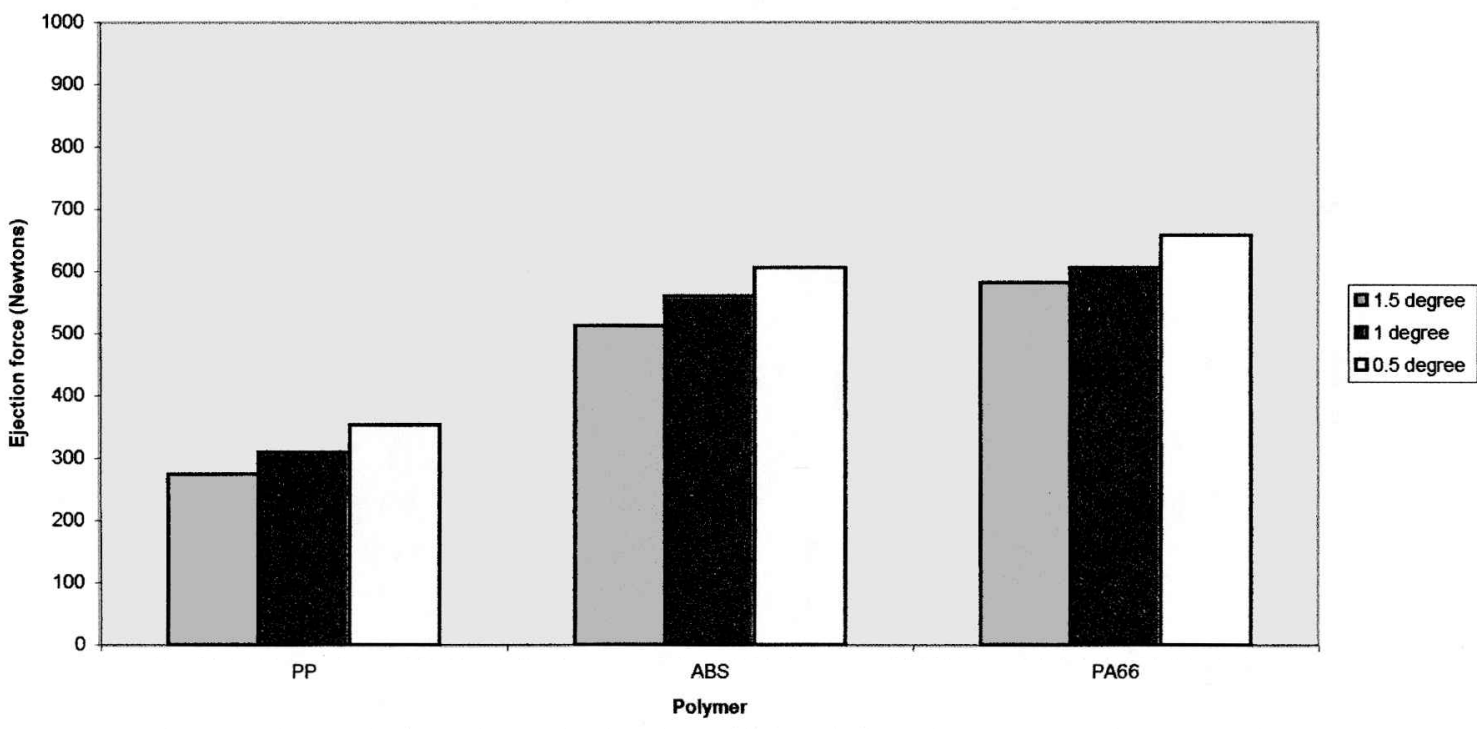

Fig. 4 Comparative effects of the experimental variables on ejection force for the same shot

\section{REFERENCES}

1 Jacobs, P. Recent advances in rapid tooling from stereolithography. In 7th International Conference on Rapid Prototyping, San Francisco, California, 1997.

2 Luck, T., Baumann, F. and Baraldi, U. Comparison of downstream techniques for functional and technical prototypes-fast tooling with RP. In Proceedings of 4th European RP Conference, Belgriate, Italy, 1995.

3 Roberts, S. D. and Ilston, T. J. Direct rapid prototyping injection moulding tools. In Proceedings of 7 th European Conference on Rapid Prototyping and Manufacturing, Aachen, Germany, 1998.

4 Janyanthi, S. Stereolithography injection moulds for direct tooling. In Proceedings of 9th European Stereolithography Users Group Meeting, 1997.
5 Heath, J. Direct tooling for injection moulding. In Proceedings of SME Rapid Prototyping and Manufacturing Conference, Dearborn, Michigan, 1996.

6 Jacobs, P. F. Recent advances in rapid tooling from stereolithography. In Proceedings of 2 nd National Conference on Rapid Prototyping and Tooling Research, Buckinghamshire College, 1996.

7 Decelles, P. and Barrit, M. Direct AIM ${ }^{T M}$ Prototype Tooling Procedural Guide, 1996 (3D Systems, Valencia, California).

8 Hopkinson, N. and Dickens, P. M. Study of ejection forces in the direct AIM ${ }^{\mathrm{TM}}$ process. In Proceedings of 9th Solid Freeform Fabrication Symposium, Austin, Texas, 1998.

9 Menges, G. and Morhen, P. How to Make Injection Moulds, 1986 (Hanser Publishers). 
10 Glanvill, A. and Denton, E. Injection Mould Design Fundamentals, 1965 (Industrial Press, New York).

11 Burke, C. and Malloy, R. In Proceedings from 49th ANTEC Conference, Montreal, Canada, May 1991, pp. 1781-1787 (Society of Plastics Engineers).

12 Hopkinson, N. and Dickens, P. M. Injection mould tooling in hours/days rather than days/weeks. In Proceedings of World Manufacturing Congress Conference, Newcastleupon-Tyne, 1999.

13 Mach. Des., Mater. Selector Issue, 1993/1994, 65(26) (Penton Publishers).

14 Material Data for ELTEX ${ }^{T M} P R W 261$ Polypropylene, June 1994 (Solvay, Brussels).

15 Material Data for Lustran ABS Ultra 2373, 1998 (Bayer AG, KU-Europa).
16 Material Data for Bergamid A65S Natural SO, 1998 (M. A. Hanna).

17 Frank, H. P. Polypropylene, 1969 (MacDonald Technical and Scientific, London).

18 Basdekis, C. H. ABS Plastics, 1964 (Reinhold Publishers).

19 Ogorkiewicz, R. M. The Engineering Properties of Plastics, 1997 (Oxford University Press).

20 Reitz, H. Comparative wear testing of SL material against SL material and aluminium relatively. Report from Danish Technological Institute Tribology Centre, 31 May 1999.

21 Kalpakjian, S. Manufacturing Processes for Engineering Materials, 1991 (Addison-Wesley).

22 Rees, H. Mold Engineering, 1995 (Hanser Publishers). 